\title{
Outcome prediction in comatose patients: significance of reflex eye movement analysis
}

\author{
A MUELLER-JENSEN, H-P NEUNZIG, Th EMSKÖTTER \\ From the Neurological University Clinic Hamburg-Eppendorf, University of Hamburg, West Germany
}

SUMMARY An analysis of oculocephalic response and vestibuloocular reflex (VOR) in 81 patients with coma from various causes showed the importance of reflex eye movements for outcome prediction. Compared with oculocephalic response testing, VOR analysis provided more evidence and allowed more precise study of ocular motility in comatose patients. In 25 patients $(31 \%)$ without conclusive or with absent oculocephalic response, a preserved VOR could be seen. The results indicated that in all cases with preserved VOR response (independent of the cause of coma) the assumption of a good outcome is justified and was correct in a maximum of $67 \%$. The unpredictability in the other cases was largely due to non-neurological factors. Ninety two per cent of the patients with abolished reflex eye movements died. The combination of absent VOR and abolished pupillary light reaction allows prediction of negative outcome in $100 \%$ and shows the paramount importance of these two brainstem reflexes.

It is well known that the analysis of the oculomotor system is of high localising value in the diagnosis of brainstem disorders. In the comatose or lethargic patient, voluntary or visually evoked eye movements cannot be evaluated. Other than spontaneous movements, the oculomotor system may be analysed by ocular reflex deviations, namely oculocephalic and caloric stimulation. Observation of these reflex eye movements is an essential part of the examination in the unconscious patient. ${ }^{12}$ The presence of full conjugate eye movements attests to the integrity of the brainstem, while dysconjugate responses or loss of reflex eye movements indicate a severe, often irreversible structural brainstem lesion. So far, many authors have dealt with this subject and caloric testing with ice water is particularly used routinely in many centres. ${ }^{2-5}$ However, only a few reports in the literature give precise information on reflex eye movements analysis with regard to outcome prediction in patients with coma from various causes. Almost all previous papers were related to series of patients with severe head injury ${ }^{4-13}$ or hypoxic-ischaemic coma. ${ }^{313} 14$

The aim of our study was to check the reliability of reflex eye movements analysis for early prognosis and

Address for reprint requests: Professor Dr A Mueller-Jensen, Neurological University Clinic Hamburg-Eppendorf, Martinistrasse 52, D - 2000 Hamburg 20, West Germany

Received 3 January 1986 and in revised form 19 June 1986.

Accepted 26 June 1986 predicting outcome in comatose patients with different underlying diseases in comparison with other commonly used clinical predictors such as pupillary light reaction and/or best motor response.

\section{Patients and method}

This analysis is based on 81 patients with coma of various causes. According to the Glasgow Coma Scale, ${ }^{15}$ the criteria for admission to the series was a state of coma with a GCS score 6 or less (table la) and duration of coma longer than 6 hours. Brain death patients were excluded. All cases were classified according to a modified Glasgow Outcome Score (table 1b). Outcome of the patients correlated with the cause of the coma is shown in fig 1 . Of those with a low Glasgow score (mean admission GCS score 4, 5) 51 patients (63\%) died or became vegetative; on the other hand, 25 patients $(31 \%)$ survived with only a minimal disability or had a good recovery. In all patients, oculocephalic response and vestibuloocular reflexes (VOR) were tested almost always immediately after admission to our medical or neurological intensive care units. More than half $(n=45,56 \%)$ were first examined within 6 hours, $61(75 \%)$ within 12 hours, and 81 $(100 \%)$ within the first day. Horizontal as well as vertical reflex eye movements were analysed. The oculocephalic response or the so-called doll's head eye phenomenon was elicited by rapid passive head turning with contraversive conjugate eye deviation. Vertical movements were tested (as far as possible) by brisk extension and flexion of the head. These manoeuvres were of course not attempted if we suspected that the patient had sustained trauma sufficient to cause a cervical fracture or dislocation. Moreover, head displacements are not advisable in patients with brainstem hae- 
390

morrhage or tentorial herniation, which may worsen with these abrupt manoeuvres.

Figure 2 shows the normal VOR in horizontal and vertical directions due to caloric stimulation. After examination of the external auditory canal and tympanum and elevating the head $30^{\circ}$ above the horizontal (for maximum stimulation of the horizontal semicircular canals), $50 \mathrm{ml}$ ice water was flushed within about 10 seconds into the canal using a small soft catheter fitted onto a syringe. For testing the conjugate upward deviation of the eyes, bilateral stimulation with $44^{\circ} \mathrm{C}$ warm water was performed. In general, absent VOR were interpreted with caution and especially vestibulosuppressant drugs (barbiturates and other sedative drugs, phenytoin) as well as neuro-muscular blockers and preexisting vestibular diseases had to be excluded as causes.

\section{Results}

In 25 patients $(31 \%)$ with no conclusive or absent oculocephalic response, a preserved VOR response

Table A/B Outcome assessment made three months after admission

\begin{tabular}{llr}
\hline Glasgow Coma Scale $^{15}$ & Table A & \\
\hline Eyes open & Spontaneously & 4 \\
& To speech & 3 \\
& To pain & 2 \\
Best verbal response & None & 1 \\
& Orientated & 5 \\
& Confused & 3 \\
& Inappropriate words & 2 \\
& Incomprehensible sounds & 1 \\
Best motor response & None & 6 \\
& Obey commands & 5 \\
& Localise pain & 4 \\
& Normal flexion to pain & 3 \\
& Abnormal flexion to pain & 2 \\
& Extension to pain & 1 \\
& None & 15
\end{tabular}

Modified Glasgow Outcome Score Table B

\begin{tabular}{ll}
\hline 1 & Dead \\
2 & Vegetative \\
3 & Severe disability \\
$4-$ & Moderate disability \\
$4+$ & Minimal disability \\
5 & Good recovery \\
\hline
\end{tabular}

\begin{tabular}{|c|c|c|c|}
\hline \multirow[b]{2}{*}{$\begin{array}{c}\text { Cause of coma } \\
\text { (n) }\end{array}$} & \multicolumn{3}{|c|}{ Modified Glasgow outcome scale } \\
\hline & $\begin{array}{c}1-2 \\
\text { Death/veget. } \\
\text { state }\end{array}$ & $\begin{array}{l}\text { 3-4- } \\
\text { Sev-mod } \\
\text { disab. }\end{array}$ & $\begin{array}{l}4+-5 \\
\text { Min disab.- } \\
\text { good recov. }\end{array}$ \\
\hline $\begin{array}{l}\text { Hypoxia- } \\
\text { Ischemia (29) }\end{array}$ & 20 & 1 & 8 \\
\hline Head injury (28) & 16 & 4 & 8 \\
\hline $\begin{array}{l}\text { Metabolic-toxic } \\
\text { coma (12) }\end{array}$ & 5 & 0 & 7 \\
\hline $\begin{array}{l}\text { Subarachnoid I } \\
\text { intracerebral } \\
\text { haemorrhage (12) }\end{array}$ & 10 & 0 & 2 \\
\hline$n=81(100 \%)$ & $51(63 \%)$ & $5(6 \%)$ & $25(31 \%)$ \\
\hline
\end{tabular}

Fig 1
Mueller-Jensen, Neunzig, Emskötter

Vestibular ocular reflex

(caloric stimulation)

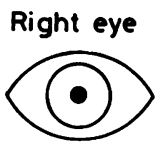

Left eye

Spontaneous position
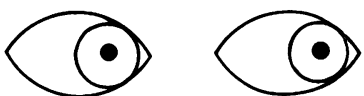

Cold water

Cold water
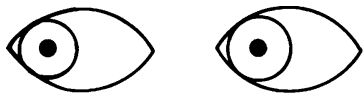

Cold water
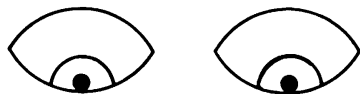

Cold water

Hot water
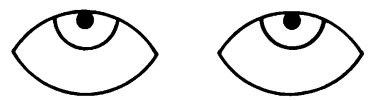

Hot water

Fig 2 Scheme of vestubuloocular reflex (VOR) in horizontal and vertical directions due to caloric stimulation.

\begin{tabular}{|c|c|c|c|}
\hline (a) & Modi & Glasgow & scale \\
\hline $\operatorname{VOR}(n=81)$ & $\begin{array}{c}1-2 \\
\text { Death/veget. } \\
\text { state }\end{array}$ & $\begin{array}{l}\text { 3-4- } \\
\text { Sev-mod } \\
\text { disab. }\end{array}$ & $\begin{array}{l}4+-5 \\
\text { Min disab. } \\
\text { good recov. }\end{array}$ \\
\hline $\begin{array}{l}\text { Tonic } n=21 \\
\text { conjugate }\end{array}$ & $14 \%$ & $19 \%$ & $67 \%$ \\
\hline $\begin{array}{l}\text { Minimal } n=23 \\
\text { or } \\
\text { dysconjugate }\end{array}$ & $61 \%$ & $4 \%$ & $35 \%$ \\
\hline None $n=37$ & $92 \%$ & $0 \%$ & $8 \%$ \\
\hline
\end{tabular}

(b)

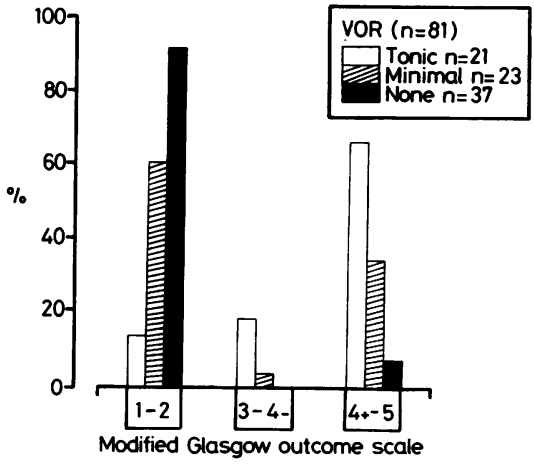

Fig 3a/b

could be seen. Because of the stronger vestibular stimulus produced by douching ice water against the tympanic membranes, in particular preserved minimal or dysconjugate VOR response due to medial longitudinal fasciculus lesions could be observed. Correspondingly, we have not seen intact oculocephalic 
response when the VOR was abolished. As a rule, VOR analysis in comparison with oculocephalic response testing provided more evidence and allowed a more precise study of ocular motility in comatose patients. In the following, we therefore only report on our VOR findings.

Figure 3 shows in tabular and graphic form the results of VOR testing correlated with the outcome. The VOR findings were divided into three types of responses: (1) tonic conjugate response which indicates the integrity of pons and mesencephalon. (2) minimal or dysconjugate responses especially of the type of internuclear ophthalmoplegia to medial longitudinal fasciculus lesions. (3) abolished VOR response.

Preserved vertical response in the absence of horizontal movements (indicating relative sparing of the midbrain) we only saw once in a case with basilar artery occlusion. The patient died. On the other hand, pathological vertical VOR with normal tonic horizontal responses (pointing to a more localised mesodiencephalic lesion) were observed in six cases. Four

(a)

\begin{tabular}{|c|c|c|c|}
\hline \multirow{2}{*}{$\begin{array}{c}\frac{V O R \text { and } P L R}{(n=81)} \\
\end{array}$} & \\
\hline & $\begin{array}{c}1-2 \\
\text { Death/veget. } \\
\text { state }\end{array}$ & $\begin{array}{c}\text { 3-4- } \\
\text { Sev-mod } \\
\text { disab. }\end{array}$ & $\begin{array}{c}4+-5 \\
\text { Min disab.- } \\
\text { good recov. }\end{array}$ \\
\hline $\begin{array}{l}\text { VOR } \phi / \text { PLR } \phi \\
n=18\end{array}$ & $100 \%$ & $0 \%$ & $0 \%$ \\
\hline $\begin{array}{l}\text { VOR } \phi / P L R+ \\
n=20\end{array}$ & $85 \%$ & $0 \%$ & $15 \%$ \\
\hline $\begin{array}{l}\text { VOR+/PLR } \\
n=4\end{array}$ & $50 \%$ & $0 \%$ & $50 \%$ \\
\hline $\begin{array}{l}\text { VOR+/PLR+ } \\
n=39\end{array}$ & $36 \%$ & $13 \%$ & $51 \%$ \\
\hline
\end{tabular}

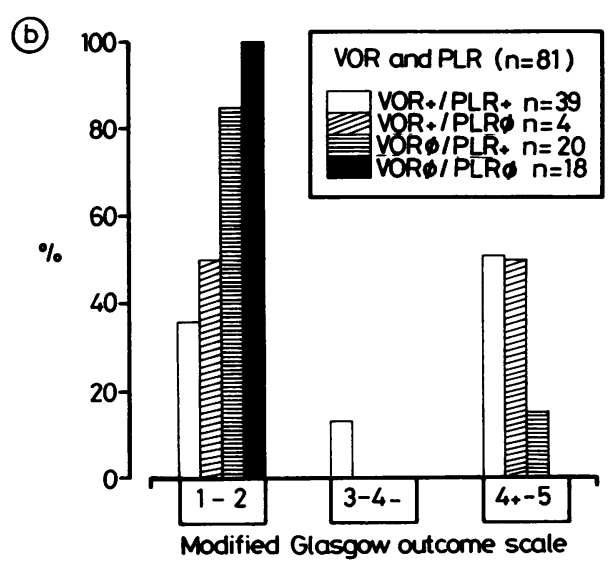

Fig 4a/b Symbol Ø means absent response. Symbol + means preserved response. patients had a good recovery, two died.

Altogether, $92 \%$ of patients with abolished VOR died (fig 3). In this group, we did not see a vegetative state. On the other hand, patients with normal tonic conjugate responses had a good recovery in $67 \%$. We found a false negative response in only $8 \%$ (three patients): one patient with later diagnosed barbiturate intoxication and two patients with severe, but transient vertebrobasilar artery insufficiency. It is important to note that in all three cases the pupillary reaction to light was positive.

Figure 4 shows the results of VOR and pupillary light reflex (PLR) testing correlated with the modified Glasgow Outcome Score. All patients with abolished VOR and PLR died. There was no false negative response. In 20 cases with absent VOR, still reacting pupils were observed. With exclusion of the three patients already mentioned the other 17 patients $(85 \%)$ died.

Figure 5 demonstrates the results of VOR testing and the best motor response according to the GCS (M

(a)

\begin{tabular}{|c|c|c|c|}
\hline \multirow{2}{*}{$\begin{array}{l}\text { VOR and } \\
\text { motor } \\
\frac{\text { response }}{(n=81)}\end{array}$} & \multicolumn{3}{|c|}{ Modified Glasgow outcome scale } \\
\hline & $\begin{array}{c}1-2 \\
\begin{array}{c}\text { Death/veget. } \\
\text { state }\end{array} \\
\end{array}$ & $\begin{array}{c}3-4- \\
\text { Sev-mod } \\
\text { disab. }\end{array}$ & $\begin{array}{l}4+-5 \\
\text { Min disab.- } \\
\text { good recov. }\end{array}$ \\
\hline $\begin{array}{c}\text { VOR } ₫ / M 1-3 \\
n=31\end{array}$ & $94 \%$ & $0 \%$ & $6 \%$ \\
\hline $\begin{array}{c}\text { VOR } ₫ / M 4 \\
n=5\end{array}$ & $80 \%$ & $0 \%$ & $20 \%$ \\
\hline $\begin{array}{c}\text { VOR }+/ M 1-3 \\
n=19\end{array}$ & $53 \%$ & $5 \%$ & $42 \%$ \\
\hline $\begin{array}{c}\text { VOR }+1 M 4 \\
n=26\end{array}$ & $31 \%$ & $15 \%$ & $54 \%$ \\
\hline
\end{tabular}

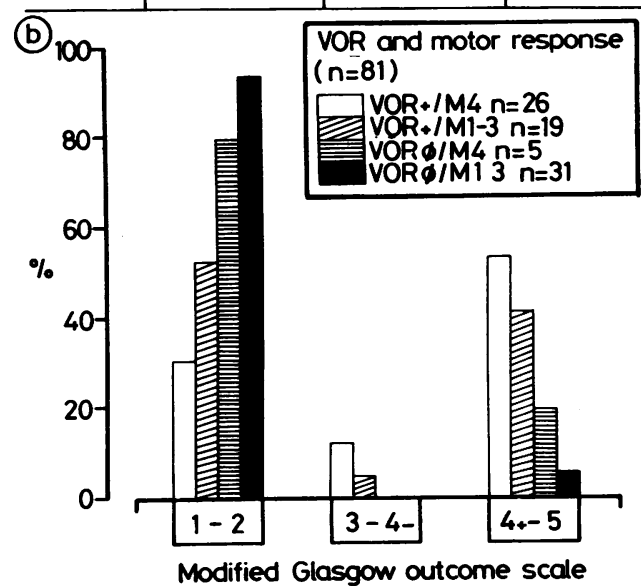

Fig 5a/b Symbol Ø means absent response. Symbol + means preserved response. 
4/M 1-3) when correlated with the outcome. The likewise high correlation of negative outcome $(94 \%)$ with absent VOR and poor motor response (M 1-3) is obvious. The false negative VOR responses are again represented by the two patients mentioned with transient vertebrobasilar insufficiency. On the other hand, normal flexion to pain and preserved VOR indicates a good recovery in $54 \%$.

\section{Discussion}

Identification of prognostic factors for reliable early prognosis and predicting outcome of patients with coma of various causes is of paramount importance. Clinical data such as age, GCS score, pupillary response have proved to be effective as indicators of outcome, especially in larger series of patients with severe head injury 679111216 or hypoxic-ischaemic coma. $^{3}$ Although reflex eye movements are not an integral part of the GCS, careful analysis of them can provide additional information on both the site and the severity of brain damage in the comatose patient. From previous communications, ${ }^{12} 17$ it is well known that bilaterally intact horizontal and vertical oculocephalic response and VOR preclude the possibility of severe brainstem lesions. Because of the stronger vestibular stimulus, although it takes a little more time and trouble to perform, the VOR is easier to interpret than the oculocephalic response and it is generally more reliable. ${ }^{217}$ In 25 patients $(31 \%)$ with absent oculocephalic response a preserved VOR could be seen.

Our results show that in all patients with preserved VOR (independent of the cause of coma) the assumption of a good outcome is justified and was correct in a maximum of $67 \%$. The unpredictability in the other cases depend on several non-neurological factors in terms of irrevocable medical complications in the further course of the disease. These influences limit the best prognostic system. On the other hand, disturbed or abolished reflex eye movements (after safe exclusion of for example, drug-induced, false negative responses) reliably indicate a negative outcome. A total abolition of caloric response usually corresponds with an extensive brainstem lesion. It is generally associated with loss of all other brainstem reflexes. The overall absence of VOR response, with preservation of in particular the pupillary light reflex may assume topographical significance, pointing to a more localised pontine lesion and is not necessarily the expression of an irreversible process. We have seen such false negative caloric response in three patients $(8 \%)$. On the other hand, 17 patients with absent VOR and still reacting pupils were observed, who all later died. This shows that in a high percentage $(85 \%)$ an abolished VOR indicates the negative outcome earlier than pupillary responses. The combination of absent VOR and abolished PLR allows prediction of a negative outcome in $100 \%$.
In present and future studies these simple clinical facts should be taken into consideration when favouring multimodal evoked potential analysis as the best outcome-predicting system for comatose patients. ${ }^{131819}$

\section{References}

1 Fisher $\mathrm{CM}$. The neurological examination in the comatose patient. Act Neurol Scand Suppl 1969;36:1-56.

2 Plum F, Posner JB. The Diagnosis of Stupor and Coma. Philadelphia: Davis, 1972.

3 Levy DE, Caronna JJ, Burton HS, Lapinski RH, Frydman H, Plum F. Predicting outcome from hypoxicischemic coma. JAMA 1985;235:1420-6.

4 Pilz P. Axonal injury in head injury. Acta Neurochir Suppl 1983;32:119-23.

5 Rodriguez Barrios R, Bottinelli MD, Medoc J. The study of ocular motility in the comatose patient. $J$ Neurol Sci 1966;3:183-206.

6 Alexandre A, Colombo F, Nertempi P, Benedetti A. Cognitive outcome and early indices of severity of head injury. J Neurosurg 1983;59:751-61.

7 Babic B, Djordejevic Z, Janicijevic M. Prognostic factors in acute head injuries-brain-stem contusion during the first week. Acta Neurochir Suppl 1979;28:153-7.

8 Cartlidge NEF, Shaw DA. Head Injury. London: Saunders, 1981.

9 Choi SC, Ward JD, Becker DP. Chart for outcome pre diction in severe head injury. $J$ Neurosurg 1983;: 59:294-7.

10 Comninos StC. Early prognosis of severe head injuries in children. Acta Neurochir Suppl 1979;28:144-7.

11 Jennett B. Assessment of the severity of head injury. $J$ Neurol Neurosurg Psychiatry 1976;39:647-55.

12 Jennett B, Teasdale G, Braakman R. Prognosis of patients with severe head injury. $J$ Neurosurg 1979;4:283-9.

13 Narayan RK, Greenberg RP, Miller JD, et al. Improved confidence of outcome prediction in severe head injury. J Neurosurg 1981;54:751-62.

14 Black P. Predicting the outcome from hypoxic-ischemic coma: Medical and ethical implications. JAMA 1985;254:1215-6.

15 Teasdale G, Jennett B. Assessment of impaired consciousness and coma: A practical scale. Lancet 1974;2:81-4.

16 Nathanson M, Bergman PS, Anderson PJ. Significance of oculocephalic and caloric responses in the unconscious patient. Neurology 1957;7:829-32.

17 Poulsen J, Zilstorff K. Prognostic value of the caloricvestibular test in the unconscious patient with cranial trauma. Acta Neurol Scand 1972;48:282-92.

18 Cant RB. Brainstem disorders and coma: Evaluation and monitoring using evoked potentials and brainstem reflexes. In: Struppler A, Weindl A, eds. Electromyography and Evoked Potentials. Berlin: Springer, 1985:181-6.

19 Hume AL, Cant RB. Central somatosensory conduction after head injury. Ann Neurol 1981;10:411-9. 